
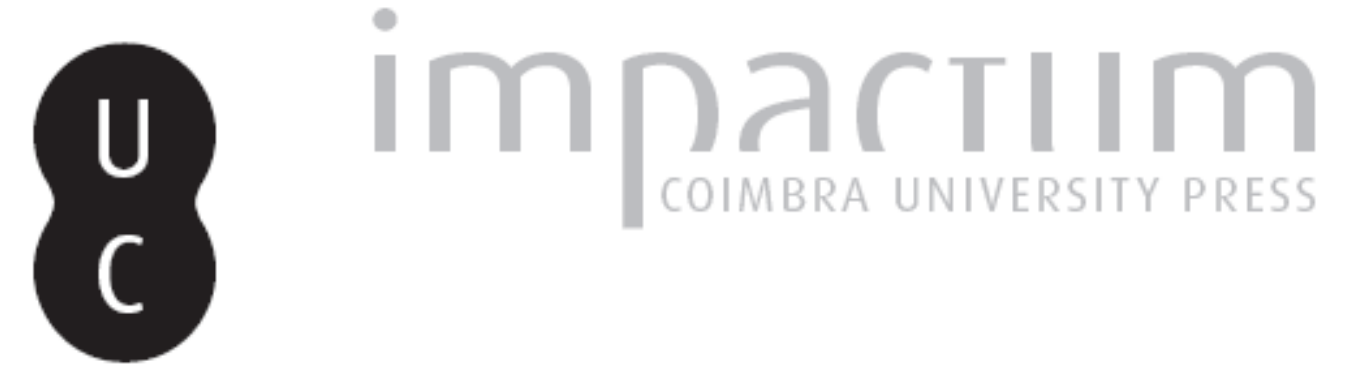

\title{
La représentation de l'alterité au temps des premières guerres de religion: trois figures de l'exclusivisme
}

\author{
Autor(es): $\quad$ Crouzet, Denis
}

Publicado por: Imprensa da Universidade de Coimbra

URL persistente:

URI:http://hdl.handle.net/10316.2/43698

DOI:

DOI:https://doi.org/10.14195/2183-8925_25_7

Accessed : $\quad$ 26-Apr-2023 13:02:22

A navegação consulta e descarregamento dos títulos inseridos nas Bibliotecas Digitais UC Digitalis, UC Pombalina e UC Impactum, pressupõem a aceitação plena e sem reservas dos Termos e Condições de Uso destas Bibliotecas Digitais, disponíveis em https://digitalis.uc.pt/pt-pt/termos.

Conforme exposto nos referidos Termos e Condições de Uso, o descarregamento de títulos de acesso restrito requer uma licença válida de autorização devendo o utilizador aceder ao(s) documento(s) a partir de um endereço de IP da instituição detentora da supramencionada licença.

Ao utilizador é apenas permitido o descarregamento para uso pessoal, pelo que o emprego do(s) título(s) descarregado(s) para outro fim, designadamente comercial, carece de autorização do respetivo autor ou editor da obra.

Na medida em que todas as obras da UC Digitalis se encontram protegidas pelo Código do Direito de Autor e Direitos Conexos e demais legislação aplicável, toda a cópia, parcial ou total, deste documento, nos casos em que é legalmente admitida, deverá conter ou fazer-se acompanhar por este aviso.

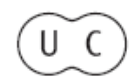



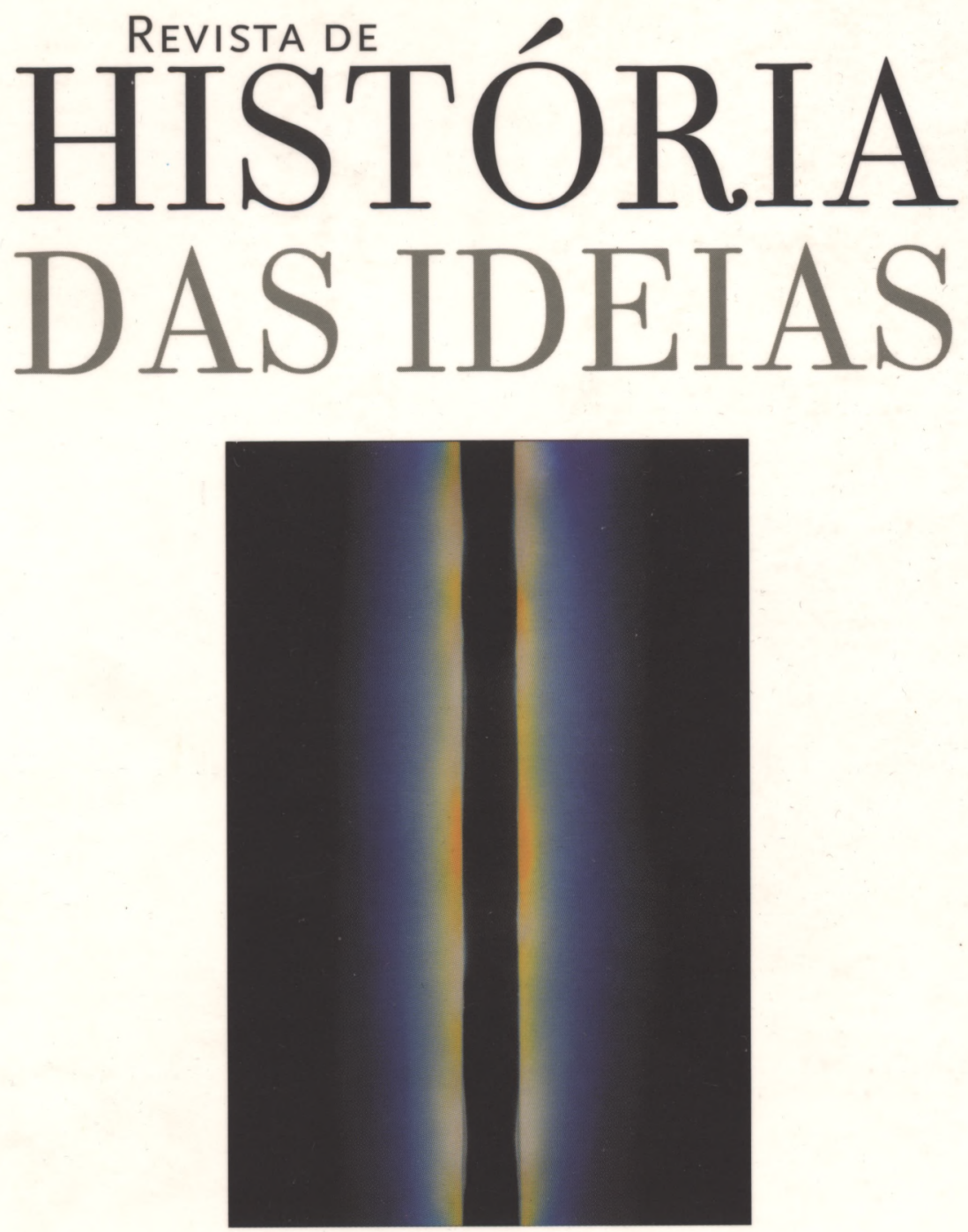

TOLERÂNCIAS, INTOLERÂNCIAS

\author{
Volume 25, 2004
}

INSTITUTO DE HISTÓRIA E TEORIA DAS IDEIAS

Faculdade de Letras da Universidade de CoImbra 


\title{
LA REPRÉSENTATION DE L'ALTERITÉ AU TEMPS DES PREMIÈRES GUERRES DE RELIGION \\ Trois Figures de L'exclusivisme
}

\begin{abstract}
Ce serait un paradoxe facile de dire, d'emblée, que l'acception moderne de l'altérité serait sortie des paroxysmes d"intolérance" religieuse que le XVIe siècle a connus, surtout en France. Car, mis à part Sébastien Castellion et encore avec des limitations, ce n'est pas, de toute évidence, sur une acception moderniste de la "tolérance" que les penseurs renaissants de la différence ont articulé leurs systèmes de conceptualisation. Si l'on s'attache en effet à caractériser la démarche du chancelier Michel de L'Hospital, il est patent que le processus de cohabitation confessionnelle autorisé par l'Edit de janvier 1562 n'entrevoit l'acceptation de la réforme calviniste que comme temporaire, provisoire. Il s'agissait d'ouvrir, en concédant les libertés de conscience et de culte aux fidèles de la religion de l'Evangile, un temps de pacification des antagonismes religieux qui devait permettre aux hommes, stimulés par la retombée des passions qui caractériserait la paix civile, de s'amender et au terme duquel Dieu leur donnerait son pardon en restituant providentiellement l'unité de foi. Mais il n'en est pas moins vrai que ce fut pour réagir contre la situation de blocage à laquelle ils étaient confrontés, pour ruser avec les exclusivismes protestant et catholique qui, à leurs yeux, risquaient de faire courir un risque mortel à l'Etat et
\end{abstract}

\footnotetext{
* Université de Paris-Sorbonne.
} 
donc à la société que le pouvoir politique se devait d'entretenir dans la justice et l'humanité, que des hommes en vinrent à inventer ou proposer une autre conception de la communauté socio-politique. Cette conception rompait avec l'ordre même des représentations reçues et, par là-même, peut constituer un palier dans l'histoire des mécanismes de glissement vers des manières de penser l'autre différemment, de le considérer de manière différente.

Ce que ces lignes souhaiteraient montrer brièvement, c'est que cette invention ne fut possible que dans le cadre d'une représentation du temps qui n'était pas plus celle des exclusivistes catholiques que des combattants calvinistes de l'Evangile. S'il y eut donc une mutation possible, en France à partir de 1560 et jusqu'en 1598, qui justifia la coexistence sur le principe que, dans un Etat, les hommes étaient d'abord des citoyens devant vivre ensemble sans s'entredéchirer au nom de leur Dieu, s'il y eut un discours possible sur le principe d'une concorde transcendant provisoirement les divergences dogmatiques, ce fut primordialement sur les bases d'une rupture dans l'imaginaire de la durée, sur les données élémentaires d'un déplacement des représentations de la temporalité. Penser l'autre sans penser la destruction ou l'occultation de l'autre ne fut possible qu'à travers le jeu d'une transformation des catégories temporelles et, par là même, par le truchement d'un autre rapport de la société humaine à la durée. Mais, comme on le devinera, penser l'autre sans le nier n'était pas pour autant l'accepter, ce fut seulement reporter dans la durée son exclusion, sa négation en l'abandonnant à la providence divine.

Mais avant d'aborder cette question, il faut, en guise de points de départ de la réflexion, s'attacher à définir les exclusivismes religieux, contre lesquels ce déplacement est mis en œuvre; et d'abord il y a le fonctionnement triomphaliste du calvinisme qui ne peut se comprendre, au temps des premières guerres religieuses, que sous l'angle d'un imaginaire cyclique, un imaginaire tendu vers un retour du temps dont le signe serait, précisément, l'abolition des idolâtries et qui, en conséquence, passerait par la transition d'un instant de violence libératrice.

\section{Une haine de l'autre qui est amour}

Les calvinistes français, à partir de la mort, accidentelle mais comprise par eux sous un angle providentialiste, d'Henri II, sortent de la clandestinité; 
cette sortie se fait par la violence, toujours plus agressive au fur et à mesure qu'il y a prise de conscience de la puissance numérique de la religion de l'Evangile et que des ministres missionnaires, venus de Genève à partir de 1555, dressent des Eglises dans des structures très militantes. Ce qui frappe alors les contemporains, c'est l'impatience des huguenots, tout se passant comme si les temps étaient courts pour eux, comme s'il y avait urgence à ce que le royaume soit délivré des signes de la pollution papiste qui, depuis des siècles, ont empêché ou obscurci toute appréhension de la Vérité. D'où la multiplication des interventions iconoclastes et des profanations, d'où, à partir de l'été 1561, des villes comme Montpellier, dans lesquelles sont déjà éradiquées la messe et les "superstitions", sont chassés les prêtres, sont enlevées ou abattues les images et croix. Et évidemment, avec le soulèvement d'avril 1562, les villes qui tombent au main des huguenots subissent le même sort, après un mois de temporisation et à l'imitation d'Orléans où le prince de Condé ne peut empêcher l'explosion d'une violence purificatrice qui se cristallise contre les images.

Contre les appels théoriques de Calvin à la patience, l'impatience prime et c'est une représentation particularisée du temps qui s'articule à ces gestes de violence exclusiviste: pour ces hommes et ces femmes qui se précipitent sur les images, piétinent les hosties, cassent les autels, brisent les vitraux, fracassent les orgues, déchirent les ornements liturgiques, le temps bascule, par la volonté de Dieu dont leurs gestes ne sont que l'accomplissement obéissant, $d$ 'une durée d'enténèbrement et de corruption à une durée d'Alliance retrouvée. Il bascule non pas dans l'inconnu d'une durée qui pourrait être angoissante ou incertaine, mais au contraire dans un ordre de répétition d'un passé déjà vécu par l'humanité, dont il est ainsi le miroir. L'imaginaire ainsi est un imaginaire cyclique, serein et rempli d'espoir voire de triomphalisme. La réformation est une re-formation qui se veut un retour, une révolution dans la durée qui emmène les fidèles de l'Evangile dans une séquence bénie de répétition. Le temps doit faire son œuvre, c'est dans son cours ouvert que sera parachevée la conquête des âmes égarées. Des rituels de libération sont ainsi théâtralisés dans les cités qui tombent dans les mains des fidèles de l'Evangile : tel celui consistant à faire monter un prêtre à l'envers sur une mule, à lui mettre la queue de la bête dans la main, à le promener aux côtés de soldats qui portent au bout de piques l'un un missel, l'autre une hostie consacrée, le dernier des ornements liturgiques, 
les signes de l'adultère avec Dieu. Puis la parodie de procession ou de charivari s'achève sur la place publique où le prêtre, descendu de sa monture, doit se déshabiller, jeter dans un bûcher ses vêtements sacerdotaux et les autres objets qui l'ont accompagné, avant de quitter l'espace de la ville ou du village. C'est ici le départ de la messe, hors de l'espace rendu à la vérité évangélique, qui est représenté dans le croisement avec la culture carnavalesque. Mais ce que l'on note immédiatement, c'est qu'il s'agit non pas de tracer dans l'espace des signes et de les mémoriser, mais au contraire de faire disparaître les signes de l'offense à Dieu. Et il en est de même pour les images, les reliques, les orgues, les vitraux.

Certes, cet imaginaire cyclique s'intègre dans un imaginaire linéaire dont le terme sera le Jugement dernier, mais il faut bien voir que, pour Calvin, par-delà la Bible, Révélation divine à laquelle l'entendement doit s'ouvrir, y percevant non pas Dieu, mais ce que Dieu a voulu et accepté de faire connaître de lui, il n'y a que "vaine spéculation". La Parole de Dieu est, ainsi par elle-même, introductrice à la prise de conscience de ce qu'il y a des limites à la faculté humaine de connaître, de ce encore qu'il y a des choses que Dieu a voulues laisser hors de la connaissance. Il y a une ignorance qui est respectueuse de la volonté divine: celle qui donc consiste à ne pas chercher à deviner les Mystères divins, à ne pas laisser la nature finie de l'homme tenter de s'approprier ce qui n'est connu que de la nature infinie de Dieu. Avoir la foi, c'est donc accepter une attitude de non-questionnement, se placer en position de respect de Dieu par la simple acceptation de ne pas empiéter sur ce que Dieu seul peut savoir. L'homme, en conséquence, ne doit pas spéculer sur le devenir, à commencer précisément sur l'imminence ou la non-imminence de l'instant du grand renouvellement. Avec Calvin, est décisive la mise en place d'une "déseschatologisation" de l'imaginaire: il devient contraire à l'ordre de Dieu de spéculer sur le devenir, de tenter de chercher à deviner l'instant du jugement dernier. Au contraire, l'homme doit détourner sa pensée de toute angoisse, même s'il sait qu'au terme des Temps viendra l'instant du Jugement.

La construction dogmatique calvinienne permet, alors de briser l'encerclement obsessionnel que le prophétisme d'angoisse avait jusque-là progressivement façonné ou actualisé. Le théocentrisme re-forme la représentation du Temps; il a ceci de positif ou d'actuel face aux interrogations contemporaines qu'il s'articule à une sortie individuelle de l'angoisse. Calvin est tout de suite, dès la première Institution, et il le 
sera encore plus dans les éditions suivantes, extrêmement méfiant et réservé sur l'Apocalypse, dont il ne donne aucun commentaire. Il recommande bien sûr d'attendre la venue du Rédempteur, dans "la Majesté inénarrable de son règne", mais hors de toute volonté de savoir, hors donc de toute anxiété, de tout sentiment panique. L'homme ne doit pas se préoccuper de connaître l'imminence ou l'éloignement de l'instant du Jugement, sa nature corrompue le rend incapable d'accéder à ce qui est de l'ordre du seul savoir divin. En tant que chrétien, il ne doit pas spéculer sur ce que Dieu seul s'est réservé de déterminer. L'angoisse devient doute de Dieu, offense à Dieu.

Le vécu de la religion est, certes, peut-être rendu plus difficile, en apparence plus âpre car plus intellectualisé par les définitions capitales de "l'élimination de la bonté divine" (Max Weber) et de l'éloignement absolu de Dieu de l'homme. Mais ce qui fait leur puissance de suggestion, c'est qu'elles ont pour compensation une évacuation de la pensée $\mathrm{d}$ 'angoisse. L'absolue transcendance divine élimine de la sphère du monde les signes de Dieu, le devenir est relégué hors du champ de l'appréhension humaine, le Jugement peut être de demain ou de beaucoup plus longtemps en avant dans la durée, nul ne peut ni ne doit en pré-juger. Il y a donc dissociation: au sein d'une durée linéaire, le chrétien doit vivre le temps dans une dynamique cyclique.

Avoir reçu l'illumination de l'Evangile dans la France de la décennie 1560, c'est avoir reçu la certitude individuelle et collective de ce que la providence divine travaille dans le présent, qu'il y a eu restitution de $l^{\prime}$ Evangile dans son authenticité et qu'il faut se mobiliser pour que cette restitution débouche au plus vite sur le règne du Verbe, pour que disparaisse tout ce qui profane la gloire de Dieu, pour que la pureté de culte et de foi de l'époque de l'Eglise primitive soit réinstaurée sans contestation aucune. Certes, lorsqu'il faut mobiliser contre le Triumvirat catholique, les libelles huguenots arguent d'un "devoir de révolte" qui, par delà les différences religieuses, devrait unir tous les fidèles sujets du roi Charles IX contre les tyrans qui gouvernent en son nom et qui lui dissimulent la pureté de la foi des fidèles de l'Evangile.

Mais entre le discours politique et les gestes collectifs, il y a l'écart de l'imaginaire de la foi même et de l'obsession vitale et vivifiante d'un devoir de pureté et de purification: pour les militants calvinistes, $l^{\text {'"intolé- }}$ rance" est alors en effet un devoir absolu, puisque, dans la Bible, Moïse a obéi à Dieu en faisant massacrer les adorateurs du Veau d'or, puisque 
encore le refus de l'idolâtrie a été ce par quoi Dieu a distingué ses élus, s'est réconcilié avec son peuple. Dieu ne supporte pas de partager son règne avec un autre Dieu qui est un faux Dieu. Son exclusivisme est extrême.

Ici, il faut faire l'effort d'une restitution probabiliste du système de représentations de ces hommes et de ces femmes qui sortaient d'un mouvement subjectif de conversion et pour qui, par leur foi en la justice miséricordieuse de Dieu, la volonté divine s'était en quelque sorte fichée en eux, déposée en eux qui ne vivaient plus que de la "nourriture" spirituelle du Verbe, du Dieu vivant. Il leur fallait faire vite, ne pas transiger, faire triompher l'Evangile hic et nunc. Car si Dieu a révélé enfin sa Vérité après des siècles de corruption, c'est parce qu'il veut qu'une histoire reprenne, parce qu'il veut que son peuple, détourné de lui par les faux prophètes de l'Eglise romaine, revienne en plénitude à lui, revienne en quelque sorte sur les pas de l'histoire, nie une longue séquence pour se replacer dans celle de jadis. La réconciliation est par essence exclusiviste, et l'intolérable, pour Dieu, serait de tolérer l'intolérable. $C^{\prime}$ est donc en un recommencement des temps bibliques et du bonheur de l'Eglise primitive que la subjectivité calviniste croit, c'est pour ce recommencement que les violents se dressent rituellement en 1562, dans la certitude que Dieu veut que sa Loi soit obéie par tous, dans l'évidence que, tant qu'il subsistera des signes d'infidélité, des hommes et des femmes continueront à se laisser séduire par les artifices diaboliques.

Le refus de l'altérité, il ne faut pas s'y méprendre, est alors témoignage $d^{\prime}$ 'une foi qui œuvre en se donnant à l'autre, en faisant tout pour que l'autre soit tiré des traverses malfaisantes dans lesquelles l'Eglise romaine l'a perdu. Il est acte de charité par lequel le croyant s'efforce de sauver des âmes perdues, de les faire venir à l'enseignement des vérités de Dieu, à la liberté chrétienne. Il ne faut pas en conséquence lire de manière anachronique le cours de cette histoire troublée. Le calvinisme ne peut pas penser l'exclusivisme de manière négative, parce que l'acceptation de l'altérité est négative dans la doctrine même de Calvin. Abolir les signes de la profanation, c'est faire revenir le monde vers ce temps au cours duquel Dieu était vénéré dans un culte pur. $L^{\prime \prime}$ intolérance" est alors mimétique, car le temps présent rejoue le temps mosaïque du peuple élu, dans une sorte de messianisme à rebours qui fait dire à un libelle lyonnais de 1562 que l'âge d'or, est de retour depuis qu'en ville toutes les pollutions ont été détruites ou rejetées. Elle est au cœur de l'imaginaire même de Calvin à Genève. 
Il faut, ici, revenir quelque peu en arrière pour mieux cerner la relation du refus de l'altérité à l'engagement dans la foi en la miséricorde divine. A l'occasion de la crise qui voit la défaite de la faction perriniste, Calvin prêche journellement. Il intervient oralement en exigeant que justice soit faite contre ceux qui sont accusés d'avoir tenté de subvertir l'ordre politique de la cité; car la réaction de la justice civile ne semble pas avoir été immédiate, sans doute par peur d'un mécontentement bernois. Les lundi 20, mardi 21, et mercredi 22 mai 1555, ses sermons sur le quatrième chapitre du Deutéronome débutent sur l'évocation de l'ire de Dieu qui vient sur les incrédules demeurés insensibles aux avertissements lancés depuis des jours et des jours. Dieu seul doit être entendu en ce bas-monde. Tous ceux qui se refusent à lui sont des dangers. Une horrible condamnation doit attendre les rebelles à la parole de Dieu, parce qu'ils ont eu connaissance de la vraie doctrine et de la bonne crainte, mais ils s'en sont retirés par leurs fautes, dans une "rage diabolique". Ils sont plus coupables que les Turcs et les papistes qui, eux, vivent sans avoir été initiés à la vérité. Dieu veut que son peuple soit un peuple un, vivant dans l'union la plus étroite et totale avec lui, au temple comme dans tous les lieux de la cité. Les "zizanies" rompent cette union aujourd'hui, comme elles l'ont rompue du temps de Moïse. Mais aujourd'hui, comme Moïse jadis l'a énoncé au nom de Dieu, un "ordre" doit être gardé, l'ordre d'un lien qui est une "droite union" sacrée. Il faut avoir en haine ceux qui sèment la discorde, les "canailles qui aujourd'huy servent le Diable, comme s'ils étaient à ses gages, et qu'ils se fussent du tout vendus mesmes pour le servir". Il y a eu "complots" et ces complots, remplis $\mathrm{d}^{\prime}$ ordure et de puanteur, sont des conspirations contre Dieu. Dieu ne veut pas que les larrons et les traîtres se mêlent au peuple, le temps est venu de se séparer d'eúx tout en priant Dieu qu'il nettoie son temple des "villenies" des "ennemis domestiques". L'éradication des méchants n'est pas cruauté, elle est témoignage de la crainte libérale que tout bon chrétien doit éprouver à l'égard d'un Dieu dont la justice est miséricorde et la miséricorde justice. L'amour, à nouveau, passe par la haine, la négation, il en est indissociable, parce que la vengeance que le magistrat doit exercer à l'égard des séditieux visera à protéger les fidèles d'être contaminés par les méchants.

Dans un sermon quelque peu ultérieur en date du 14 juillet 1555, qui commente le Psaume 149, la violence calvinienne, chargée d'une haine mimétique des imprécations bibliques, surgit encore pour justifier 
la mise à mort des méchants. Les fidèles de Dieu reçoivent la mission de défaire les méchants et les incrédules, et les combats de Moïse sont évoqués, Moïse n'épargnant pas même les membres de sa famille, venu avec l'"épée sanglante" au milieu des siens et criant à ceux qui aiment Dieu de le suivre et de tuer tous ceux qui se trouveront en chemin. La vengeance sanglante de Moïse ne rompt pas avec son "esprit débonnaire", tout comme la violence de David contraint à répandre le sang humain en de nombreuses guerres. La violence n'a pas été violence $d^{\prime}$ 'un mortel, mais la violence salutaire de Dieu qui arme le courage des siens pour exécuter sa violence. Il fait mal aux bons chrétiens de faire couler le sang, et, lorsqu'ils le font couler, ce n'est pas par colère ou par passion, ce n'est pas dans la cruauté, c'est par un "devoir" qui leur fait considérer uniquement Dieu et leur fait penser à tous ceux qui vivent au péril de leur âme. Faire mal aux impies, c'est faire bien aux pieux en évitant qu'ils ne soient corrompus par les paroles malheureuses des impies, en évitant encore que leurs âmes ne soient séduites par Satan et ne meurent à Dieu, c'est dire un amour de Dieu, avoir la crainte de Dieu. Mais l'important est que la haine est synonyme alors d'amour, elle est acte d'amour, elle est nécessaire à l'amour. Elle ce par quoi l'autre pourra cesser d'être autre ou de risquer d'être autre, dans un appel à ne plus vivre que dans le suivi des commandements bibliques. L'altérité n'est donc pas pensée comme un point de non-retour, elle est une humanité plastique, d'autant plus plastique qu'elle n'est que péché et que, pour le cas où la providence l'amènerait dans le droit chemin de la foi, elle ne pourrait pas résister à l'infinie bonté de Dieu.

Si Calvin donc use d'une rhétorique intégrant la véhémence ou la haine, c'est parce qu'il a une conception violente de son ministère. Parler, c'est témoigner d'une vocation à dire les exigences de Dieu, c'est être donc en guerre contre le mal, contre Satan. Le pasteur, tel que Calvin le définit et tel qu'il le vit en lui, est un guerrier de Dieu, un "défenseur de la piété sincère". Calvin vit, écrit et déclame sa charge comme celle d'une sentinelle, $d$ 'un guetteur obéissant à un commandement qui lui vient de Dieu et qui le porte à être en éveil constant, à ne rien laisser passer qui puisse contredire le Dieu vivant. En conséquence, le pasteur ne peut et ne doit pas quitter ou abandonner le "lieu" qu'il lui a été commandé de garder. Ce serait le livrer aux ennemis, à ceux qui appartiennent à Satan. Calvin est un homme qui vit sa vocation, intérieurement, comme partie prenante d'une guerre d'une dureté et d'une violence extrêmes, durant 
laquelle toute faiblesse a des conséquences catastrophiques, durant laquelle le guerrier de Dieu qu'il est ne doit jamais fléchir, dans un engagement de toutes les secondes. Face au ministre et à sa parole, il y a des tueurs qu'il faut tuer spirituellement pour que la maison du Christ ne soit pas détruite, pour que la sanctification des fidèles ne soit pas ruinée. Abattre les loups qui environnent cette maison, qui sont parfois cachés sous son toit, c'est instruire par la parole de Dieu, dire et redire la parole de Dieu comme seule doctrine chrétienne. Il faut se dresser contre l'altérité, ne jamais lui laisser de répit, savoir qu'elle est toujours prête à renaître et repartir à l'offensive, mais aussi avoir conscience qu'elle peut toujours être gagnée à la puissance de la Vérité, même au prix d'une violence qui l'affaiblirait et qui revivrait les grands élans du peuple biblique de l'Alliance.

Et Calvin, avec humilité, dit et nomme ce qu'est la haine et l'amour, autour de lui. Mais, en disant et en nommant la haine, il faut le dire, il use d'un moyen destiné à permettre aux incrédules de venir à Dieu. Avoir la foi, c'est être en guerre. Le risque est de laisser une marge, même minime, d'existence à l'infidélité, de laisser une possibilité, même infime, à un retour en arrière dans une histoire qui a vu le mensonge recouvrir la Vérité. Le risque est encore, surtout, d'être passivement ou activement criminel à Dieu et de se séparer de Dieu. Les calvinistes français de la première guerre de Religion témoignent, il faut le dire, de cette conscience combattante façonnée par Calvin et par les ministres venus de Genève. Ils se pensent comme les acteurs d'un triomphe de la Vérité, leurs gestes sont des paroles de gloire divine par lesquels le temps présent doit se déliter au profit d'un retour du temps de l'Alliance.

Une représentation cyclique de la durée ordonne ainsi la pensée de la violence huguenote de la décennie 1560 . Elle permet, à partir de juin-juillet 1562, le glissement d'une violence jusqu'alors limitée aux signes d'offense à Dieu vers les prêtres et moines, accusés d'être ceux par qui Satan résiste de manière sanglante à la victoire inéluctable de l'Evangile. Ce sont eux, disent les chansons et les libelles, dont il ne faut plus tolérer la survivance, parce qu'ils maintiennent les hommes dans l'oubli de Dieu, les poussent à être aveugles à la restitution de la Vérité, les inclinent à toujours ignorer le Dieu vivant, les incitent à résister par le sang et le feu aux bras de Dieu que sont les fidèles de l'Evangile. Ils sont ceux qui entravent ou retardent le mouvement providentiel de révolution temporelle. Ils doivent disparaître de la terre, il faut les exterminer, obéir à Dieu en les exterminant. 
Il n'empêche que l'"intolérance" huguenote est une "intolérance" moins meurtrière que l'exclusivisme catholique: elle se cible, dans les cités et les espaces qui passent sous le contrôle de la réforme protestante, sur les "razés" tout en acceptant temporairement la coexistence avec les papistes privés de leurs prêtres, de leurs lieux de culte, de leurs médiateurs saints. Dans la mesure où elle perçoit le temps comme immédiatement ouvert aux bienfaits infinis et inéluctables de la providence divine, comme en mouvement nécessaire de retour vers une pureté perdue, dans la mesure le temps passé doit revenir, dans la mesure encore où elle est certaine de la puissance même de l'Evangile restituée, elle ne peut qu'être assurée de ce que les barrières subjectives à la Vérité, par l'enseignement donné par les ministres, par la puissance de la Parole de Dieu, finiront par être, un jour imminent, brisées chez tous ceux qui, pour l'instant, demeurent dans l'oubli de Dieu. Il y a donc, parallèlement à une immense espérance qui porte à l'éradication des signes et des agents de l'infidélité, un optimisme calviniste dans le rapport à l'autre: appréhension que la Toute-puissance de Dieu ne pourra que faire venir à elle ceux qui continuent à l'ignorer dans le présent. Il s'agit de les mettre en condition de recevoir la Vérité en les privant de ce qui peut les entretenir dans leur enténèbrement et en les aspirant ainsi dans le mouvement providentiel de révolution cyclique, de retour vers la foi de l'Eglise primitive. L'extermination des prêtres n'est pas à interpréter alors comme l'expression d'une négation de l'autre; elle n'est que l'aveu de ce qu'une certaine raison des gestes doit accompagner le monde nouveau que la providence divine est en instance de faire surgir: la certitude que, pour que l'altérité cède le pas devant la puissance de la Vérité, il faut se résoudre à se faire violence à soi-même, dans l'exercice même d'une violence que les événements rendent nécessaires, dans une mise à mort de ceux qui forment comme un écran à la révélation d'une volonté divine miséricordieuse. D'où des rites signifiant, à travers les souffrances infligées aux clercs, qu'ils sont la force satanique qui a fait vivre l'humanité dans une folie, dans l'inversion : corps émasculés, vidées de leurs intestins, exprimant ainsi que ce n'était pas Dieu que les prêtres adoraient, mais leur bas-ventre, leurs passions. Corps qui façonnent, dans cette justice qui leur est appliquée, un théâtre du passage, de la transition de l'infidélité à la fidélité, qui marquent à la fois une fin et un recommencement.

C'est ici où, rapidement, il faut une seconde fois en revenir à Calvin lui-même, parce que le réformateur de Genève donne la clef de cet 
exclusivisme, de son sens sur lequel il ne faut pas se méprendre par anachronisme. Etre papiste, le réformateur ne cesse de le dire et de le redire, c'est être hors de la constance, cheminer dans le "doute" perpétuel qui conduit les hommes à se fabriquer "leurs devotions à plaisir" pour mieux tenter d'attiédir ou de forcer une justice divine dont ils doutent. Et, à l'origine de ce doute, il y a l'illusion que l'homme peut "estre maistre de sa vie", en être le "conducteur", l'illusion qu'il peut se commander à lui-même ce qui est juste et ce qui est injuste, suivant ainsi "son semblant, son cuider"; $l^{\prime}$ illusion qui fait qu'en s'imaginant aller vers Dieu, il profane Dieu. Le chrétien qui vit dans les superstitions papistes est aux yeux de Calvin un chrétien angoissé, en recherche permanente d'une sécurité qu'il ne peut pas trouver ou qui se défait de lui dès qu'il s'imagine l'avoir rencontrée. Cette angoisse relève de la croyance que l'homme a une capacité de faire son salut par ses propres forces, par ses œuvres mêmes. Elle est impure au sens où elle cache, dans ses tréfonds, obscurément ce qui est une haine de Dieu puisqu'elle soupçonne sans cesse Dieu de ne pas être pleinement un Dieu d'amour. Il est impossible d'aimer véritablement en ayant en soi la peur à tout instant.

Ces hommes qui cultivent la mauvaise crainte détestent donc secrètement Dieu, et leur vie n'est, pour le réformateur de Genève, qu'une longue et absurde bataille engagée inconsciemment contre Dieu, un Dieu qui leur apparaît avant tout assis sur son "siège judicial" afin de "punir les transgressions". Cette lutte inconsciente contre Dieu se traduit par l'usage des pratiques superstitieuses, l'adoration des "pollutions" que sont les idoles, les "menus fatras et cérémonies de nulle valeur", 1 'ordre extérieur de l'“apparence" d'une religion qui n'est pas une religion du cœur. Une crainte panique monte sans cesse dans l'esprit de ces hommes, une crainte qui leur suggère toujours et toujours plus encore de chercher à apaiser Dieu par des mérites qui se relativisent au fur et à mesure qu'ils s'accumulent et qui les font vivre dans une "singerie". Il est évident alors que le bon chrétien doit se mobiliser pour faire disparaitre de la terre tout ce par quoi, images, ornements, autels, livres, l'homme est maintenu dans la mauvaise crainte et donc les superstitions. Toute "intolérance" est une pédagogie, au sens où elle dit la Toute-puissance d'un Dieu aux commandements de qui il faut obéir. Il y a eu inversion du rapport à Dieu, il faut bien l'appréhender dans la pensée calvinienne: l'amour de Dieu des papistes cache un amour de soi, créature corrompue et infiniment vouée au mal qui s'érige puissance de faire son salut, 
il dissimule ainsi une haine de Dieu. Pour que la vraie foi soit retrouvée, il faut inverser cette inversion: l'homme doit se savoir péché, ordure, souillure, il doit se nier lui-même pour ne plus mettre d'espérance que dans la gratuité miséricordieuse du salut donné par Dieu. La conscience d'un temps cyclique va donc de pair avec un théocentrisme. L'exclusivisme commence par soi-même.

A la mauvaise crainte, Calvin substitue en effet la bonne crainte. La bonne crainte est pénitence, aveu sans cesse réitéré que les fautes connues et confessées à Dieu ne sont rien par rapport à toutes celles que Dieu discerne. Aveu que toute pensée qui se réfère à soi, qui pense à soi autrement que comme néant et souillure, est mauvaise pensée, infidélité. Une "crainte" faite de révérence et d'humilité, reconnaissante de l'absolue souveraineté de Dieu et ouvrant sur une sagesse qui est un engagement à régler la vie selon le désir de Dieu et non pas selon la fantaisie du péché. Une "crainte" qui, jadis, a détourné Job de "s'adonner à des spéculations qui les tiennent en branle sans aucun profit, sans aucune fermeté"; l'appréhension de la "ferme et certaine connaissance de Dieu envers nous". A vrai dire, la bonne crainte, face à Dieu, n'est plus de la crainte, et comme on le verra, la haine dont elle s'arme, n'est que de l'amour.

La bonne crainte, alors, détourne l'homme de l'"audace" ou de l'outrecuidance" de vouloir pénétrer jusque dans le plus profond des secrets de Dieu, de vouloir s'ingérer de le contraindre à la miséricorde. Elle restitue l'ordre vrai Créateur-créature: I'homme s'avoue sujet et créature pécheresse. Il se détruit comme lieu de penser Dieu, il devient pensée de Dieu à travers l'acceptation de ce que Dieu se démontre dans les Écritures, est présent en vie, parle en l'homme qui écoute, son "cœur en avant". La bonne crainte s'exprime dans la pénitence comme dans la violence.

La bonne crainte, si elle récuse la peur face à Dieu, est une manière de faire peur, de signifier une haine à l'égard du péché. Craindre Dieu comme Dieu veut être craint, c'est haïr l'autre. La bonne crainte est aussi action et donc parole au sein desquelles se confondent ou se fusionnent, par delà les apparences, la haine et l'amour. Il ne faut pas s'y tromper, le mode d'expression dont use la bonne crainte, pour rendre compte de la conversion du fidèle à Dieu, est une expression souvent remplie de haine, mais d'une haine instrumentalisée comme un amour. Lorsque l'on compulse les registres du Consistoire de Genève, on ne peut qu'être frappé par la violence même de certaines comparutions qui mettent aux prises des hommes ou des femmes convoqués et Calvin. 
Et alors surgit, de la part de ceux qui sont confrontés au réformateur, le sentiment qu'il ont face à eux un homme rempli de "haine". Calvin doit se défendre d'ailleurs d'être un homme de cette "haine": lorsque Guillaume du Bois l'accuse d'avoir de la "haine" à son égard, il réplique qu'il s'agit d'un mensonge; Guillaume du Bois a parlé avec impudence. Jamais, ajoute Calvin, il ne lui a porté une "haine" pour des motifs personnels; la seule "haine" qui le tient est la haine contre les vices dont il est rempli. Elle n'est donc pas personnelle, elle ne s'attache pas à l'individu même, elle est dirigée contre les passions qui sont en lui et qui, l'éloignant de Dieu, sont présentes dans toute créature. Calvin explique ensuite pourquoi il a de la "haine" contre les vices de Guillaume du Bois. Les mots claquent sèchement, violemment. Guillaume du Bois n'est pas un honnête homme, parce qu'il a fait le commerce clandestin des livres en France, en les "survendant" aux pauvres fidèles du royaume dans le seul but de s'enrichir. De plus, "il avoit esté traître à Dieu et à l'evangille troublant les povres consciences", car il avait répandu la rumeur, jusque dans Genève même, selon laquelle Calvin aurait rétracté sa condamnation de l'idolâtrie. Calvin obtient l'emprisonnement de Guillaume du Bois dès le lundi 3 janvier 1547.

Il faut ici poser la question suivante. Certes Calvin accepte la haine comme partie prenante de son discours, il ne la nie pas même s'il déclare fortement que la haine que lui attribue ses contradicteurs est une haine qui n'est pas d'ordre personnel. La haine, dans cette perspective, est une manière de rendre active la bonne crainte. Le travail du Consistoire, tel que le réformateur l'a voulu, s'apparente à un travail de réapprentissage du langage qui veut avoir une dimension métaphysique et au cœur duquel la haine jouẹ le rôle déterminant de fil d'Ariane permettant de sortir du labyrinte du péché. La haine est un instrument qui doit susciter l'éveil de la personne convoquée à la haine de soi et donc à l'amour de Dieu, elle est ce par quoi une sortie de l'inconscience peut être suggérée. Elle est le truchement qui doit faire venir l'impie à la crainte révérencieuse de Dieu. Elle est en ceci l'inverse de ce qu'elle paraît, elle est témoignage d'amour, elle est amour. Le rôle du consistoire est d'amener le pécheur à sortir des ténèbres dans lesquels il se complaît en croyant connaître une lumière qui n'est qu'obscurité. La haine est la face cachée de l'amour. Aimer l'autre, être l'acteur d'une solidarité réversible, c'est haïr ce qui détourne l'autre de la vérité, dire avec haine ce qui éloigne l'autre de l'amour de Dieu, être véhément contre le mal qui le tient. 
La haine fait partie de la crainte, parce qu'elle est amour à l'égard de l'autre et donc parce qu'elle vise à attirer l'autre dans l'appréhension des promesses divines. Le consistoire, il faut bien le dire, n'est donc pas pensé par Calvin comme un espace répressif, il est le théâtre d'une mise en éveil du pécheur. Il ne veut pas réprimer ou sanctionner, il veut enseigner.

L'intolérance" entendue au sens d'une négation de l'autre est la face cachée d'une puissance d'amour, d'une immense acceptation de l'autre comme celui pour lequel tout doit être entrepris pour tenter de le faire sortir de son altérité, pour le guider vers Dieu. La tolérance du mal condamne celui qui tolère comme celui qui est dans le mal. Le temps se vit donc à rebours, dans une "révolution" qui fait revenir les hommes vers des modèles passés d'alliance, vétéro - ou post-testamentaire.

Il faut ajouter que, lorsque les calvinistes doivent se résoudre en 1563 ou 1568 à accepter la paix de religion, c'est parce qu'ils se trouvent en situation difficile sur le plan militaire. Le réalisme ici joue, mais ne rompt pas avec la certitude d'une victoire imminente sur les ennemis de Dieu. La paix doit permettre à la Parole restituée de Dieu d'opérer dans le royaume contre l'idolâtrie intérieure et donc elle poursuit, avec d'autres moyens, le rêve exclusiviste. C'est-à-dire qu'il s'agit pour eux moins d'accepter l'offre de coexistence religieuse en tant que donnée structurelle de la vie terrestre, que d'utiliser cette coexistence pour se donner les moyens, d'autre moyens, de faire travailler à travers le royaume la puissance d'illumination et de conversion qu'est la prédication de l'Evangile, la Parole d'un Dieu vivant.

Une fois donc entrevu le fait que, pour les calvinistes, $l^{\prime \prime}$ intolérance" se façonne dans la mimésis vétéro-testamentaire et dans le rêve d'un temps retrouvé, par l'instrument d'une haine qui est amour, il faut en venir à l'exclusivisme catholique. La représentation du temps, ici, est différente.

\section{Un rêve d'extermination}

Au nom du Dieu sauveur et rédempteur la violence fut aussi collectivement mise en œuvre comme l'instrument simultanément offensif et défensif de l'Eglise romaine. Le terme apparaît dans libelles et pamphlets: il ne faut pas "tolérer" l'ennemi de Dieu. Toute "tolérance" est envisagée de manière péjorative, et est donc à refuser. 
C'est dans leurs gestes mêmes que les foules catholiques relatent leur dynamique d'agression articulée à une pensée exclusiviste selon laquelle il ne peut y avoir qu'une seule foi dans le royaume, la foi des ancêtres. Unité de l'Etat et unité de la religion sont inséparables. A partir du début de l'année 1560 en effet, les scènes macabres vont se répétant, fixées pour la postérité dans l'Histoire ecclésiastique des Eglises de France de Théodore de Bèze ou dans le Martyrologue de Jean Crespin. Tantôt les agressions, toujours collectives, visent un individu seul dans la foule dont le corps peut être éviscéré, mutilé horriblement. Tantôt, à l'occasion soit de l'investissement d'une ville par une armée, soit d'une action d'éradication préméditée, soit encore d'un conflit opposant les deux communautés religieuses pour le contrôle de l'espace urbain, les huguenots sont massacrés en un nombre variable, cinq, dix, vingt victimes, cent, plusieurs centaines, et plusieurs milliers dans le Paris d'août 1572, souvent exposées ensuite au regard de leurs co-religionnaires comme pour leur enseigner la victoire d'un Dieu qui, précisément, ne tolère pas d'infidélité à sa justice.

Cette disponibilité collective à la violence et à la guerre de Religion s'explique parce que la religion "papiste", dans toutes ses expressions du milieu du siècle, est un immense appel à la destruction de l'"hérésie", à une œuvre de justice voulue par Dieu.

Tout d'abord parce que ses fidèles, depuis plusieurs décennies, ont été aspirés dans une intense grande violence intérieure. Depuis le début du XVIe siècle s'est comme enflée dans la société irrésistiblement une angoisse devant le devenir, et le déclenchement des guerres de Religion sonnera vite comme une libération. Le contexte de la scission religieuse est un contexte de dramatisation offensive de la relation à Dieu. Tous les canaux d'information fürent peu à peu envahis par une parole prophétique, qui portait à la connaissance de tous que le châtiment de Dieu était en instance de s'abattre sur une humanité parvenue au point le plus total du péché, une humanité pénétrée par l'Autre, Satan. Parce qu'aux derniers temps, l'Autre doit venir et faire des hommes des autres à Dieu.

Le refus de l'autre relève là encore d'une représentation du temps, certes différentes mais posant le présent comme l'instant d'une tension décisive; et si les violences catholiques se démarquent par leur intensité des violences protestantes, c'est parce qu'elles sont sous-tendues par un imaginaire eschatologique. Il y a la perspective subjective d'une urgence qui pousse à la destruction de l'autre, mais une urgence d'autant plus 
forte qu'elle doit être immédiate et totale. Le salut des fidèles se joue dans un temps court qui est le temps de la fin des temps. Il ne faut donc pas tergiverser, il faut refuser toute pratique ou tout projet conciliateur. Le Christ ne peut pas être associé à Baal, tout ceux qui accepteront la cohabitation du Christ avec Satan, non seulement se condamneront eux-mêmes pour l'éternité, mais leur faiblesse emportera avec elle tout le peuple de Dieu. Les derniers temps du monde sont là et l'hérésie en est un signe. Tous ceux qui auront transigé et ne se seront pas figés en des guerriers de Dieu quand le Christ viendra avec le glaive de feu dans sa bouche seront damnés pour l'éternité. Eschatologie, angoisse et violence se fondent pour produire une culture de la violence. Tout a d'ailleurs commencé plus tôt, vers 1530-1540.

La prédication du jacobin Dyvolé à Provins, durant le Carême 1561, dans un contexte de troubles grandissant, reprend une thématique identique: le royaume de France est bibliquement dit être sous le coup de la malédiction de Dieu, dont les hérétiques sont les signes. Il est sur le seuil de la grande Tribulation, d'un temps de violences inouies: "prophetisa à la France sa ruyne et désolation prochaine, et il l'appela par plusieurs fois et en plusieurs sermons, miserable et de Dieu maulditte".

Parallèlement, toute une intelligentsia de clercs utilise l'imprimerie pour enseigner qu'il ne peut y avoir de salut que dans la mise à mort des réformés. Dans de multiples libelles, le prêtre Artus Désiré ne cesse de redire que la présence des hérétiques est un signe indubitable de la fin des Temps, "du dernier temps, où maintenant nous sommes". Seul l'amendement peut sauver de la damnation le peuple qui a rompu par ses péchés avec Dieu. La violence, et c'est l'important, est dite obligation humaine, car c'est par elle que les fidèles retrouveront l'état sotériologique d'Alliance et pourront se tenir, au jour du Jugement, parmi les élus. Elle sera une violence de Dieu, qui soudain affranchira le catholique de sa culpabilité dans le geste même de mise à mort de l'impie. Tolérer l'impie, c'est appeler sur soi et sur le peuple dont on est membre toujours plus de division et donc toujours plus de châtiment. Vivre aux côtés de l'autre, accepter l'existence de l'autre, attendre même que l'autre cesse d'être autre, c'est soi-même devenir autre à Dieu.

La guerre comme l'agression sont justes, implacablement justes, parce que le meurtre de l'hérétique est une justification de la créature faite par Dieu à son image. Le sang que nombre de meurtriers catholiques exhibent publiquement sur leurs vêtements est une manière de lustration. Tolérer 
l'autre est criminel, car l'autre est un séducteur, qui risque de mettre à mort des âmes innocentes qui se laisseront séduire.

La puissance de l'imaginaire prophétique de la fin des Temps fait la puissance même de la violence qui éclate dans les mois qui précèdent le déclenchement même des guerres de Religion, exercée sur des huguenots qui sont simultanément les signes d'une colère eschatologique de Dieu à l'égard d'une humanité toute entière abandonnée à la charnalité, et les moyens pour cette humanité de signifier son retournement vers Dieu. Elle est une violence d'une extrême intensité et cruauté par laquelle les violents, possédés par l'obsession de regagner leur salut, se glissent dans l'ordre prophétique du Jugement de Dieu qu'ils imaginent en instance de réalisation; ils rejoignent immédiatement et mystiquement Dieu dans la violence qu'il a prophétisée devoir accomplir sur les corps de ses ennemis, en déchiffrant l'abandon de ces corps à Satan. Il faut la guerre, le massacre le plus sanglant possible, pour que Dieu se remette à aimer d'amour les hommes, pour que Dieu oublie l'infidélité et l'offense. La mimétique est à la fois vétéro-testamentaire et johannique. Dieu est un Dieu avant tout de colère et de jalousie. Sa justice doit être accomplie et l'autre doit périr.

C'est-à-dire que la guerre est sainte, guerre de croisade à laquelle appellent les prêtres et les moines à travers tout un réseau de légitimations traditionnelles, mais aussi surgissant dans l'immédiateté d'une justice divine dans laquelle les fidèles se glissent à l'occasion des événements de violence. L'ennemi de Dieu, celui qui sort d'une Eglise confirmée par la tradition et par la durée même de son histoire comme une institution divine, est malédiction, macule qui ne peut être lavée que par le sang. Dieu a commandé la mort dans l'appel lancé au peuple à lapider tous ceux des enfants d'Israël qui auront forniqué avec Moloch, ou encore à faire cendres de leurs corps. Le prêtre Antoine de Mouchy enseigne ainsi au roi que, puisque les huguenots paillardent avec Satan, ils méritent le feu comme la fille du sacrificateur qui se prostituait (Lévitique $21,{ }^{9}$ ). Parallèlement, Dieu a dit que le blasphémateur doit mourir par lapidation (Lévitique $\left.24,{ }^{14}\right)$, " [... ] parquoy les hérétiques, non seulement blasphémateurs du nom de Dieu, ains de Dieu mesme, comment pourront ils estre exempts de peine [...]". L'idolâtre doit, selon les paroles venues à la bouche de Moïse, être puni par le glaive (Exode $\left.22,{ }^{27}\right)$. De ces violences, le juste ne pourra que se réjouir, et "[...] lavera ses mains au sang du méchant". Le huguenot est un idolâtre parce qu'il s'adore lui-même en se donnant à un faux Dieu qui lui permet de ne pas 
jeûner, de ne pas faire pénitence. Investigation est faite de tout ce qui peut, cette fois-ci dans le Nouveau Testament, légitimer la violence: le Christ est aussi prouvé avoir fait appel à une justice éradicatrice, par la référence à $l^{\prime}$ Evangile selon saint Matthieu (18, ${ }^{6-9)}$ : "[...] qui scandalise et offense un de ces petits icy qui croient en moy, il luy est plus expédient qu'on luy pende une meule de moulin au col et qu'on le jette au profond de la mer. Malheur au monde pour les scandales, car il est nécessaire que scandales adviennent, toutesfois malheur à l'homme par qui scandale advient, Que si ta main ou ton pied t'empesche, coppe le et jette le de toy." Le Sauveur de l'humanité, entre autres multiples citations, est également allégué pour avoir proclamé: "je persécuteray mes ennemis, je les ay attaincts, et ne suis point retournay jusques à ce qu'ils ont esté mis à fin".

De plus, peut-être plus dramatique encore dans le système de représentations que les prédicateurs et polémistes s'efforcent de promouvoir, les hérétiques sont comme une maladie pour le corps du peuple dont ils font partie et qu'ils cherchent, sans relâche et avec une volonté que rien ne semble vouloir arrêter, à contaminer. Ils sont une peste, une gangrène, ou encore une pourriture qui se développe peu à peu dans un organisme sain. La conception corporaliste de la société civile légitime la mise à mort; car le roi, en tant que chef, tête du corps, a le devoir divin de retranchement. La mutilation est l'unique moyen pour empêcher que ne s'étendent à l'ensemble du corps les flux de mort qui sont dans certains des membres qu'il fait fonctionner normalement en harmonie les uns avec les autres dans une communauté de bien. L'autre est identifié au venin, au poison, à la pourriture, à la mort.

Mais surtout, si l'on veut comprendre les ressorts de cette pulsion d'agression contre le corps de l'autre, de ce refus de "tolérer" ou supporter l'autre, il faut la rattacher à une culture spécifique qui produit une vision spécifiquement dramatique de celui qui vit dans la différence religieuse. L'appréhension d'une exigence divine de violence est justifiée par des images certifiant que le huguenot ne doit pas, ne peut pas être considéré comme un vivant parmi les autres, il n'est qu'un corps sans âme, qu'il faut donc traiter sans pitié aucune; c'est un polémiste catholique qui affirme que "le diable est en la teste des hérétiques", les réduisant à l'état animal: "c'est pourquoy quand une personne est hérétique, il est appellé loup: le paillard est appellé pourceau, chien, cheval hannissant: un ambitieux et cruel est appellé lion: un envieux est 
appellé chien en l'escriture; et le fin et trompeur est appellé renard". Le disciple de Calvin, parce qu'il est censé vénérer un dieu qui n'est qu'une illusion diabolique, est dénoncé comme ayant été saisi intérieurement par le diable, par une idole qu'il adore et qui est en lui, une "[...] grande statue d'or, d'argent, d'airain, de fer et de bric qui est l'invention du cerveau humain"; il n'est plus qu'une apparence de l'image créée par Dieu à sa ressemblance. Aucune hésitation ne doit, aux yeux des prédicateurs et des polémistes de l'Eglise romaine, s'interposer entre l'exigence divine d'extermination et l'acte de mise à mort. Tuer n'est pas pécher, c'est au contraire aimer Dieu, aller au devant d'un désir de Dieu, accomplir un geste innocent.

On le voit, les structures d'appréhension de l'altérité sont ici inversées par rapport à celles qui régulent l'imaginaire calviniste. Face à l'autre, le combattant huguenot, mû par la bonne crainte de Dieu, adopte une posture optimiste qui exige une haine d'amour. Seuls les prêtres sont exclus de cette espérance en l'autre, parce qu'ils ont déclaré une guerre à Dieu qui leur fait martyriser les vrais fidèles. Leurs morts doivent témoigner de ce qu'aucune force humaine n'est en mesure de s'opposer à la volonté providentielle de Dieu, elles doivent aider ceux qui sont dans l'altérité à prendre conscience qu'ils ont été enfermés dans une ignorance de Dieu, qu'ils sont autres à Dieu. Elles sont une pédagogie de ce que Satan peut être repoussé, de ce que son règne est désormais battu en brèche. Et les destructions iconoclastes participent de cette rationalité elles-aussi qui doit permettre à la créature façonnée par Dieu à son image de retrouver la voie de Dieu, après avoir été égarée dans l'altérité par des superstitions maléfiques. A l'opposé les violences catholiques traduisent un autre regard sur l'autre : l'autre est perdu à Dieu, il ne peut pas être rappelé à Dieu, il faut qu'il disparaisse de la terre car il porte en lui une force de mort qui, même si elle peut sembler plier devant la puissance glorieuse de Dieu, est toujours en mesure d'en revenir à Satan. L'autre ne peut plus être le même que soi, il doit être donné à ce vers quoi il est allé en se séparant de l'Eglise catholique et romaine, la mort, Satan. Il appelle sur lui la violence conçu comme un devoir, comme le signe de l'amour de Dieu.

Cette violence est pure puisque violence de sujétion à l'ordre divin. Du fait de cette innocence des gestes et des actions de ceux qui s'abandonnent à elle, elle ne s'arrête pas là, elle défigure, pour désigner implacablement les hérétiques comme ceux dont Dieu a prédit qu'ils se 
sépareront de lui toujours par désir de satisfaire leurs corps. Ce n'est pas par hasard si, au cours des grands massacres, les cadavres des huguenots sont traînés rituellement dans les boues, laissés sur des fumiers, ou jetés à la voierie; ils sont ainsi habillés d'ordure, défigurés et déshumanisés, comme pour déclarer qu'ils ont perdu leur humanité en perdant leur âme, qu'ils n'ont plus rien de commun avec la créature faite par Dieu à son image: ils sont morts à Dieu, ils sont pourriture et immondicité pour avoir commis l'adultère spirituel avec Satan, et la violence les révèle en leur vérité d'immondicité. Le même processus de déshumanisation se retrouve dans les multiples, "infinis" coups qui martèlent les corps morts. Ils sont destinés, en rendant informes les corps, à marquer la séparation des protestants de l'Evangile d'avec Dieu: coups qui dénotent l'aspiration collective à participer à une geste prophétique de vengeance de Dieu, à entrer dans l'ordre du temps de la colère divine, à participer d'une durée eschatologique au sein de laquelle le Christ à la langue de feu reconnaîtra les siens parce qu'il les verra combattre à ses côtés. Les foules assomment les victimes "jusqu'à perdre toute forme humaine".

Une autre expression de la violence perçue comme accomplissement prophétique est celle qui infernalise le corps de l'hérétique, en inscrivant sur lui des marques qui rappellent les peines que les diables font et feront souffrir en enfer, pour l'éternité, aux réprouvés. On ne peut qu'être frappé par la fréquence des mutilations pratiquées sur les visages des massacrés et fonctionnant selon un autre registre signifiant que celui de la justice étatique: arrachage des yeux, sectionnement du nez et des lèvres, essorillement. Par la pratique de ces mutilations, la mort de l'hérétique semble comme théâtralement anticiper sur l'enfer, elle semble comme faire glisser le temps terrestre vers le temps eschatologique au cours duquel le Christ à la langue de feu précipitera vers les béances infernales les damnés; elle participe du Jugement de Dieu, à travers la coïncidence avec la description d'une peine infernale donnée en complément d'un des grands textes de la fin du XVe siècle, le Grand Kalendrier des bergiers: la vision de serpents et crapauds rongeant les mains, nez, oreilles et yeux des damnés.

Parallèlement au masque d'horreur infernal posé sur l'hérétique par les acteurs de sa mise à mort, il y a aussi une manière de faire mourir l'hérétique par où il a péché. Ici, encore, un mimétisme de l'enfer qui est le lieu de l'application aux réprouvés de la loi du Talion. Le corps de l'hérétique devient le lieu qui prophétise son châtiment. Ainsi, en enfer, 
les friandises et mets recherchés par les gourmands et les luxurieux se transmuent en fiel, venin et amertume, disent les textes. Or le huguenot est accusé par la polémique catholique romaine de refuser le jeûne non pas par foi mais uniquement pour satisfaire sa gourmandise, et peut-être le supplice subi par un drapier d'Orléans en 1572 théâtralise-t-il la mort infernale à laquelle il sera condamné éternellement pour avoir mangé chair en Carême ? Il est attaché à un poteau, et on le force à dévorer de l'excrément humain avant d'être massacré. Le monde de la violence devient un théâtre de l'enfer, par la mise en scène d'une manducation symbolique: ce sont encore les cadavres dont les bouches sont remplies de feuillets de bibles en français, condamnation pour avoir selon les

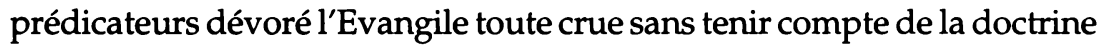
des pères de l'Eglise. Et à ces cadavres condamnés à souffrir par quoi ils ont péché, les violents crient: "vous avez tant aymés ces livres manges en à ceste heure vostre saoul". L'enfer, les catholiques y mènent encore prophétiquement les hérétiques en les abandonnant à la manducation des chiens, qui évoquent les chiens dévorants dont Robert le Roquez a la vision en 1560, dans un grand poème eschatologique, qu'ils attendent en enfer les réprouvés; en les jettant aussi dans des puits, autre symbole de la bouche d'enfer, et peut-être encore en précipitant leurs corps dans les rivières.

L'important est qu'il y a deux plans de représentations qui se surimposent: la violence catholique, d'une part, est une violence enseignante de ce qui attend dans l'Au-delà l'ennemi de Dieu. D'autre part, elle témoigne d'une subjectivité profondément et fortement eschatologique, qui entraîne les acteurs catholiques à se glisser eux-mêmes, par leurs gestes, dans une chronologie d'imminence.

Tous ces rituels convergent pour montrer une violence panique qui met en scène le Jugement de Dieu, le Temps prophétique de la venue de Dieu séparant ceux qui Lui ont été fidèles de ceux qui, pour satisfaire leur chair, ont obéi à la Bête apocalyptique. Les violences sont actes de sacralité par lesquels l'homme s'unit au Christ accomplissant l'ordre des Temps, actions mystiques de saisie par l'Esprit, de possession et d'union culminant dans des projets de croisade contre les hérétiques. Il a été procédé à l'étude des tensions que cette imposition spirituelle génère face à la puissance temporelle. Aucune loi humaine n'est susceptible de contredire la Loi de Dieu. Contre les ordonnances iniques du Prince, les prophètes de Dieu tendent à justifier que le "peuple s'attribue de soy 
mesme la puissance du glaive"; la liberté de conscience est contradictoire de l'ordre de Dieu qui est unité. La paix, dans un royaume qui connaît la division de foi, "ne merite pas le nom de paix".

La guerre est donc une guerre sainte parce qu'elle fait surgir une présence merveilleuse, eschatologique de Dieu parmi les siens. Dès le premier grand massacre catholique, qui advient à Sens le 12 avril 1562, l'action de purification est relancée ainsi par la nouvelle reçue triomphalement que "dedans le temple Sainct Hilaire" un crucifix a tourné "le dos de soy mesme contre le dos du temple de la religion". Le miracle a une signification eschatologique; il dit l'approbation divine devant les corps mutilés et déchiquetés et traînés triomphalement par les rues de la ville, comme il le redit au petit matin du 24 août 1572 dans le Paris de la Saint-Barthélemy, quand s'achève l'"exécution" ordonnée par la monarchie des chefs militaire du protestantisme: une aubépine refleurie à contre-saison et perlant de gouttes de sang, dans le cimetière des Saints-Innocents, vient certifier au peuple parisien la satisfaction de Dieu de voir sa vengeance accomplie et l'attente divine d'un parachèvement de l'éradication de l'hérésie. Et c'est alors, sur les 7-8 heures du matin, que commence le grand massacre populaire, dans cette proximité sensible d'une présence du Christ de la Passion qui dit l'ordre de violence des hommes l'ordre d'un amour retrouvé de Dieu.

L'originalité historique de ces années de conflits de religion tiendrait donc dans l'évidence que, si la violence et la guerre sont reconnues et instituées comme justes et pures par l'imaginaire des clercs qui se posaient comme les défenseurs de l'Eglise romaine, elles furent spontanément vécues par les fidèles comme une participation mysticisante à l'action et à la présence d'un Dieu vengeur, comme une participation à un instant eschatologique, comme un acte de sainteté qui intervenait au sein d'une chronologie de fin des Temps. En ce sens, l' "intolérance" papiste, le refus de toute conciliation, relève d'une foi active, panique qui permettait aux fidèles catholiques de s'imaginer les bras de Dieu. A la différence du calvinisme au sein duquel, du fait d'une structure cyclique de la pensée, la haine est synchrone d'un amour débordant, pour les catholiques il y a partage parce que, précisément, la linéarité de la représentation du temps introduit à une diachronie: $c^{\prime}$ est la nécessité de la haine divine qui ouvre sur l'amour de Dieu. Mais il est important de noter que le refus de l'autre, pour le catholicisme exclusiviste qui monte en force jusqu'à l'époque de la Ligue, s'articule à l'imaginaire d'une durée imminente et immédiate 
au cours de laquelle, par la violence la plus intense et exterminatrice, serait refaçonnée l'union à Dieu.

Et aux lendemains du massacre de la Saint-Barthélemy parisienne fleurissent les écrits qui chantent qu'enfin les malheurs du peuple de France, divisé par l'hérésie, sont terminés. L'exécution royale des huguenots est donc proposée à la conscience collective sous la forme d'un acte messianique. Des médailles sont fondues pour glorifier la royauté, signifiant que la violence dont elle revendique d'avoir eu l'initiative ouvre un temps béni d'union à Christ. Le sens de la première médaille est de fondre la violence collective dans la violence divine du roi, de prendre possession d'elle; car la croix, que le roi a fait triompher et pour laquelle il a exercé sa justice, témoigne d'un ordre messianique d'union du peuple à celui qui est sur terre le vicaire de Dieu. Le combat du peuple a été celui du roi, un combat qui certifie à tous le salut: "Aussi fut comme vraye enseigne des militans en l'Eglise chrestienne, portée tousiours depuis ce vingt quatriesme jour, pour signal es chappeaux des bons catholiques et vrais subjects du Roy, comme Ezechiel la veid marquer par l'Ange es frons des fidelles". La seconde médaille insiste sur l'héroïsme du roi, nouvel Hercule couvert de sa peau de lion et abattant l'hydre abominable à l'aide de sa massue et d'un flambeau ardent; Charles IX est le monarque dont la geste infiniment glorieuse prédit que, sous peu, si tous demeurent fidèles à la Loi de Dieu qui vient d'être ainsi formidablement exaltée "[...] nous pourrons encor/ Voir luire icy le temps et siecle d'or/ Et nostre Roy acquerra grand's louanges, D'avoir domté tant de monstres estranges".

Les chants triomphaux ne cessent de glorifier le règne de Charles IX, sans que l'on puisse discerner s'il s'agit d'œuvres de commande destinées à renforcer l'image sacrale de la royauté ou si le catholicisme prophétique en vient provisoirement à se reconnaître dans le roi justicier de 1572 . Un grand espoir de paix eschatologique monte, qui scande la louange du roi de France indissociée de celle, éternelle de gloire et de puissance, du Roi des rois: "Qui par sa bonté immence/ Donne à nostre Roy puissance/ De vaincre ses ennemis,/ Les uns chassez hors de France, / Les autres sont à mort mis. / Benissons le Dieu parfaict/ Qui au Roy faict ceste grace/ Que l'ennemi soit deffaict". Enfin et désormais, doit l'emporter la prière sur la tension de violence, prière à Dieu que l'infâme race des hérétiques soit par sa volonté "[...] du tout annihilée, / Consommée et mise au ban,/ Et que la France desolée/ Vive en paix 
sans nuls debats". Une immense espérance, alors, se donnait à vivre aux fidèles de la religion catholique et romaine, espérance de ce qu'immédiatement vienne un temps d'union retrouvée avec Dieu.

Le refus de l'autre, dans ces mises en perspective eschatologiques, apparaît comme la fin même de l'histoire humaine en mouvement de s'accomplir. La réconciliation ne pourra advenir pleinement que lorsque l'autre aura totalement disparu. Ce désir d'oblitération de l'altérité donne lieu à l'écriture de textes glorifiant la violence dans la paraphrase même de la Bible. Ainsi vient en mars 1569, à l'annonce que la guerre est victorieuse pour l'armée royale, le Cantique de victoire par lequel on peut remarquer la vengence, que Dieu a prise dessus ceux qui vouloient ruyner son eglise et la France, qui est rédigé par et imprimé par Robert Le Mangnier. Y est exaltée la figure d'un Dieu tonnerre, Dieu furieux, dont les hommes n'ont été que les instruments: "Nous les vismes Seigneur, abbatuz par monceaux / Nous les vismes trenchez en dix mille morceaux/ Remarquant en cela qu'elle estoit ta vengence/...Aussi l'as tu monstré, lors que tu as permis/ Que les corps atterez de tous tes ennemis/ N'eussent vuydes d'esprit l'honneur de sepultures:/[...] Car les chiens affamez, et mesmes les oyseaux / Se sont jusqu'au crever rempliz de leurs boyaux,/ Les loups qui ont senti tant de charongnes mortes,/ Ont de fain assaillz, le bois abandonné,/Pour prendre ce repas que leur avoit donné,/L'eternel qui punit le vice en telles sortes./ Aussi c'est toy, Seigneur, c'est toy seul, qui as peu/ Confondre et massacrer, par le glaive, et le feu/ Noz haineux... / C'est toy qui as enflé la poitrine, et le cœur,/ De nostre jeune duc, que tu as faict vainqueur".

Dieu, alors, s'adresse au roi pour lui commander de poursuivre cette durée eschatologique en persévérant dans la mise à mort et la persécution des hérétiques: "Entend donc maintenant à ces preceptes miens:/ Si tu trouves jamais vivant parmy les tiens/ Un qui ayt butiné ma maison, et mon temple,/Et qui ayt de ce jour eschappé mon effort,/ Je veux sans delayer qu'il soit mis à mort,/ Et qu'aux oyseaux du ciel soit donné pour exemple.../ Tu n'auras point d'esgard si c'est un grand seigneur, / Car je suis l'Eternel songneux de mon honneur,/ Tu sais comme Saül, lequel j'avois voulu/ Oindre pour gouverner Israel mon esleu,/ Refusant mettre Agag au tranchant de l'espée,/ Qui avoit mon honneur, et mon peuple souillé, Fut d'un sceptre si beau aussi tost despouillé,/ Et d'estranges frayeur sa poictrine frappée. / C'est pourquoy je ne veux qu'un seul reste vivant/ De ce troupeau meurtrier,... / Je t'enjoins donc, 
ô Roy, d'avoir escris au cueur/Mes saincts commandemes, qu'avec toute rigueur/Les vieux Roys tes ayeulx ont tenuz en la France". En cas contraire, si le roi refuse cette injonction, le châtiment s'abbattra inexorablement: "La faim, la peste aussi, te mineront par tout, / Mon cousteau, ma fureur, courront de bout en bout/ De tes païs perduz, sans que tu me resistes. / Car c'est moy, c'est moy seul, qui fais d'un forgeron/ D'un chartier, et d'un serf, d'un simple vigneron,/ Un roy tel que tu es: et $d$ 'un berger champestre,/ Un monarque puissant, superbe,, et sourcilleux,/ Et puis le ravallant quant il est orgueilleux,/ Aux vers, aux chiens, aux poux, qui le donne à les paistre".

\section{Un autre imaginaire}

Reste, une fois isolées et caractérisées ces deux formes distanciées $\mathrm{d}$ 'adhésion militante à une foi impliquant la nécessité sotériologique du refus de l'autre, à en venir à l'acceptation de l'altérité qui a pu intervenir de façon concomitante ou concurrente, en ces premières années de conflits et de luttes. Et qui, il faut immédiatement le dire, n'est une acceptation que des apparences.

Il faut ici énoncer un préliminaire. Il y eut des calvinistes, dont Calvin peut-être lui-même en certains instants de la séquence 1559-1562, qui furent méfiants face à l'impatience de leurs co-religionnaires, qui cherchèrent une solution de temporisation. Avec l'Edit d'Amboise de 1563, les calvinistes, par effet même de leur impuissance à parvenir aux fins de leur rêve conquérant d'Alliance, durent accepter la coexistence religieuse, avec comme contre-partie la liberté de conscience et une liberté limitée de culte. Même si durant les deuxième et troisième guerre civile renaît le rêve exclusiviste et réapparaît l'imaginaire d'une éradication de l'idolâtrie jusqu'aux racines, il n'en est pas moins vrai que la dynamique de l' intolérance" ne retrouve plus sa puissance antérieure. Sur la défensive, le protestantisme bascule lentement d'une espérance exclusiviste et triomphaliste qui reposait sur l'imaginaire d'un temps cyclique peu à peu vers un eschatologisme qui le porte à s'accepter comme minoritaire au milieu des idolâtres dans un temps d'épreuves qui est le temps au cours duquel Dieu teste les siens par des souffrances et des contre-signes pour, au jour de son jugement, les rassembler autour de lui. D'où une "intolérance" mesurée, qui est une conduite de défense contre un 
sentiment d'échec qui ne s'avoue pas à lui-même et qui, si elle exclue l'autre des plans de Dieu, n'en accepte pas moins, dans l'ordre de la cité, une coexistence méfiante avec lui. C'est cette approche qui, en fin de compte, favorise l'acceptation pourtant difficile par les calvinistes de la victoire catholique qu'est l'Edit de Nantes.

Une fois ce préliminaire établi, il faut en venir à l'invention non pas de la "tolérance" au sens moderne dont il a déjà été envisagé qu'elle était anachronique, mais de l'idée de concorde au sens d'une union des cœurs entre les membres d'une société que Dieu a créée telle, dans le cadre d'un Etat qui la régit, pour que précisément ces membres puissent vivre en humanité, sans s'entredéchirer les uns les autres comme des bêtes sauvages. Disons-le en guise de préliminaire obligé, la France, par delà des espaces ponctuels dans certaines hautes vallées alpines, par-delà l'atypie polonaise, réalise, sous la pression des événements et du fait du télescopage des exclusivismes, une invention novatrice à partir de janvier 1562. La paix d'Augsbourg, si elle avait reconnu le luthérianisme en tant que "religio", n'en avait pas moins été limitative: elle avait débouché théoriquement sur une territorialisation de la religion. La cohabitation ne devait pas être instituée dans le cadre des unités étatiques qui devaient rester unies dans une seule foi, mais dans le cadre de l'espace même de l'Empire. En France, c'est l'Etat qui accepte la coexistence, au sein même de son territoire et avec certaines limitations, de deux religions, rompant avec l'idée selon laquelle une organisation politique qui tolère en son sein une autre religion que la religion établie se place sous le jugement de Dieu et est vouée à la destruction. Il faut se représenter la rupture immense que cette innovation impliquait. C'est d'ailleurs ce qui peut expliquer son échec sur le court terme: il fallut près de quarante ans pour qu'elle s'impose de manière durable.

Et les réactions des adversaires de la politique de Michel de L'Hospital et de la régente Catherine de Médicis montrent bien que l'Edit de janvier a été reçu comme un acte de rupture: zélateurs de l'honneur de Dieu et de l'amour pour leur roi, des hommes qui se nomment les "habitants de Paris" adressent à Charles IX, à sa mère et aux seigneurs du conseil une supplique dans laquelle ils parlent du "trouble incroyable auquel ils sont mis et constituez" depuis que l'Edit a été rendu public. Ils disent qu'il n'est pas possible que Dieu et le diable soient honorés en même temps et que la "plus cruelle guerre du monde" attend le royaume. Depuis le meurtre de Cain par Abel, il n'y a eu que la violence parmi les hommes 
et la discordance de religion appelle une plus grande violence, irréductiblement. Le choc est là, face à un Edit qui est perçu comme une césure et qui n'a pu être imposer au Conseil du roi que par une "imposture la plus pernicieuse".

C'est un drame infini qui surgit dans l'imaginaire parisien de ces mois qui précèdent l'explosion de la première guerre civile, au point de laisser dire une volonté de quitter la capitale: "non que les habitans de Paris veullent ou désirent plonger leurs mains au sang de leurs ennemys, car l'honneur de Dieu, le commandement de leur prince et leur naturel qui est d'estre doulx et facille ne le peuvent permettre, mais ilz délibèrent de se retirer hors de leur ville, quitter le royaulme, leurs maisons et biens plus tost que de demeurer en la terre en laquelle telles choses adviennent". Quant au Parlement de Paris, dans les remontrances qu'il fait publier, il n'hésite pas à voir dans l'Edit de janvier l'événement par lequel tout s'effondrera, par lequel le royaume passera de l'ordre au désordre: "pour le faire court, tous les liens ordonnez de Dieu pour la conjonction, société, et amytié des hommes, seront rompus pour la permission des deux religions". Un royaume ne peut pas être policé par l'effet d'une "sagesse modaine", il s'expose par là à la prédiction de Jérémie (chapitre XIII): la paix ne donnera que la bouleversement. Et le Parlement conclut en citant la parole "infaillible du Christ selon laquelle tout royaume divisé sera désolé" (Matthieu XII). Cette évocation de la "sagesse mondaine" est cependant très parlante de la conscience des opposants à la publication de l'Edit de janvier de ce que la loi royale est une loi qui va à contre-sens $\mathrm{du}$ bon gouvernement, qu'elle est une innovation dans le cadre d'un système de pensée que ne discerne dans l'innovation qu'un mal. Il y eut traumatisme et angoisse face à la loi royale, parce qu'elle était comprise par les tenants de l'exclusivisme comme un péril absolu pour leur salut. Pour comprendre cette mise en perspective, il faut souligner, comme cela a déjà été présumé, que l'Edit de janvier est construit et conceptualisé sur une invention.

Là encore, cette invention relève d'une représentation bien spécifique du temps qui renvoie à une théologie particularisée: celle des évangéliques français. Contrairement à ce que l'on peut penser l'acceptation de l'autre n'implique pas, de la part de ses promoteurs, un projet d'autonomisation du politique et du religieux, du temporel et du spirituel. Elle est dépendante $d^{\prime}$ une foi au sein de laquelle se détache la conscience augustinienne d'un péché infini de l'homme, voué à ne jamais pouvoir connaître 
Dieu par ses forces, voué à ne faire que le mal lorsqu'il cherche à aller par lui-même, par ses mérites vers Dieu, voué à se tromper lorsqu'il se met profanatoirement à la place de Dieu en prétendant supputer sur les incertitudes dogmatiques ou sur l'imminence de la fin ou du retour des temps. L'évangélisme est une foi qui neutralise toute initiative humaine dans le champ de la relation à la transcendance. L'acceptation de l'autre est le revers d'une passivation assumée qui se révèle d'une intensité d'attente providentialiste extrême.

Dans l'épître rédigée à l'intention d'Achille Bocchi, Michel del'Hospital observe que l'intelligence humaine, même aidée des sens humains, ne peut qu'être précipitée, par la puissance de la Faute, vers de multiples erreurs, elle ne peut qu'être trompée par la fausse apparence des choses, et, lorsqu'elle tente d'appréhender les choses inaccessibles aux yeux (oculis impervia), elle est comme une arme émoussée lancée contre le plus résistant des objets. Il faut se défier et se garder d'elle. Ce qui relève de Dieu ne relève pas de l'homme et de ses facultés finies, qui le fixent dans de basses sphères dont, tout seul, il est incapable de sortir de sa propre initiative. Toute épistémologie de soi doit, aux yeux de Michel de L'Hospital, conclure en l'inanité de son objet. Certes, la science peut donc décrire la nature, les révolutions du soleil et de la lune et des étoiles, mais elle ne doit pas et ne peut pas aller au delà de cette mission. Michel de L'Hospital veut dire, ainsi, qu'elle est un non-sens et un péril lorsqu'elle amène l'homme à se substituer à Dieu: essayer de comprendre les "causas", c'est tenter de chasser les "auctores rerumque Deos" du ciel; c'est se plonger dans des "filets" que de chercher "la lumière dans la lumière" et donc se brûler. Michel de L'Hospital retrouve ici, à nouveau, la métaphore du vol que les auteurs chrétiens des premiers siècles avaient employée, car les "ailes liquéfiées", l'homme sera jeté du haut du ciel comme l'insensé Icare qui a jadis oublié les commandements de son père et donné son nom à la mer Icarienne. L'eau, engloutissant dans les profondeurs de ses abîmes l'âme impure, est un symbole de mort, comme dans l'épisode de la tempête, tandis que le soleil est l'image de Dieu. Elle attire vers elle l'âme perdue à Dieu, qui met sa foi dans elle-même, dans un amour qui est humain puisqu'amour de soi, alors que le véritable amour se traduit par l'occultation de soi.

La propension des "âmes mortelles" est, en conséquence, l'ignorance de l'ignorance, et c'est cette ignorance qui fait que la condition humaine tend à être tristement malheureuse, depuis la naissance jusqu'à la mort. 
Essentiellement, l'ignorance se projette en une course inconsciente en avant qui a pour fin d'occulter l'ignorance même, de la rendre invisible à celui qui se complaît en elle: il faut reconnaître, souligne Michel de L'Hospital, qu'il est donc naturel à l'homme de se tromper, et que l'homme, du fait de la chair qui est sa marque et sa faille, possède en lui la folie, "perpétuelle compagne", "l'erreur d'une âme allant sans fin à l'aventure". Le chrétien, en conséquence, ne doit pas chercher à se substituer à Dieu, il ne doit être que foi dans la bonté et la miséricorde de Dieu, il doit se faire néant face à Dieu.

La représentation du temps n'est ni cyclique, comme chez les guerriers de l'Evangile que sont les huguenots, ni finaliste comme elle l'est pour les combattants de Dieu qui basculent dans une eschatologie de croisade. Pour les Evangélistes, la vision du devenir des temps est indifférenciée, elle est indéterminée, abandonnée à la Toute-puissance divine: une durée dans laquelle, instant après instant, la grandeur absolue de Dieu seule, hors des tentatives $\mathrm{d}^{\prime}$ accompagnement que l'homme s'imagine de manière erronée pouvoir mettre lui-même en œuvre, est en mesure de se manifester. Le temps n'est pas théologiquement définalisé, il l'est anthropologiquement, dans une procédure de désengagement humain. $C^{\prime}$ est une transformation capitale qui est en œuvre dans la pensée de Michel de L'Hospital et de ceux qui supportent sa gestion des événements entre 1560 et 1562 . Ce ne sont pas, à ses yeux, les hommes qui sont en mesure de faire avancer l'histoire par leurs actes ou leurs vouloirs; seul Dieu est le maître de l'histoire et l'acceptation de l'autre est une manière de reconnaître et de saluer et d'accepter cette Toute-puissance. La concorde est l'expression d'un théocentrisme absolu, mais qui prend place dans le cadre d'un imaginaire neutralisé de la durée: le temps devient ainsi une catégorie stabilisée dans un mouvement de succession des instants.

A une conception augustinienne de l'homme, l'évangélisme articule le salut par la foi. Dieu est à la fois une Dieu de justice et de miséricorde, de jalousie et d'amour. L'Incarnation, dans la mise en scène d'une immense humilité, a été acte de pardon et d'effacement du sacrilège d'Adam et Eve. L'immense miséricorde de Dieu s'est manifestée de la manière la plus éclatante qui soit, car l'homme, "ingrat et ennemi", a été racheté au prix de la vie et du sang du Fils. A été réalisée la promesse des saintes prophéties, par laquelle avait été annoncé l'effacement de la Faute, lavée dans le sang: c'est l'amor suprême qui a éteint le péché et dont la "gratia major" a racheté "nos, exsortes, alienos, falsa colentes numina", "nous, exclus, 
étrangers, adorant de fausses divinités", dans un don gratuit (gratuito) qui touche "chacun et tous" à la fois (in sortem numerumque). La foi en Dieu épouse cette appréhension de la miséricorde divine et cette acceptation de cette totale dépendance qui place la volonté humaine dans l'espérance de la juste puissance ( $f a s$ ) de Dieu. Elle est, Michel de L'Hospital le dit et le redit, abandon à la certitude de l'amour même de Dieu, conscience de la liberté donnée gratuitement par Dieu d'aller vers lui, de la grâce d'être dans la justice divine. Justification par la foi, mais sans prédestination: tous les hommes ont une grâce latente en eux qui peut les amener vers Dieu, grâce à une foi "nourricière", alma fides, en l'amour de Dieu. La Vérité n'est fermée à aucun homme, elle est en mesure de travailler avec une force qui dépasse l'entendement.

C'est dans ce cadre que l'idée de concorde ou plutôt l'idée de refus des "intolérances" ou exclusivismes peut se développer, à partir aussi $d^{\prime}$ une inversion des figurations. Michel de L'Hospital se différencie des catholiques exclusivistes au sens où il ne voit pas dans le calvinisme un signe eschatologique appelant à la violence. Il se différencie aussi des protestants parce qu'il n'imagine pas que l'homme soit en mesure d'apprécier lui-même si l'une des vérités est supérieure à l'autre et si le temps, cycliquement et providentiellement, est venu d'un règne évangélique succédant à un règne des ténèbres. L'homme n'est pas en mesure de savoir si l'autre est vraiment autre. Pour le cas où il soupçonne que cette altérité est réelle, il ne doit pas s'ingérer de vouloir la réduire par ses propres forces, car si altérité il y a c'est parce que Dieu l'a voulue. Seul Dieu a la puissance de la réduire, et comme Dieu est avant tout amour, ce sera dans l'amour, dans l'amendement, et non dans la violence, que la question de l'altérité sera réglée, par Dieu seul. Si le calvinisme est là, au milieu d'une peuple chrétien, c'est pour des raisons autres: à l'origine, dit-il, depuis le début du siècle, il y a la perversion de l'humanité qui est sortie des bonnes mœurs jadis cultivées par les ancêtres. Depuis le début des guerres d'Italie, les hommes se sont corrompus: la justice s'est vendue à la partie la plus offrante, les clercs ont préféré l'or à la prière et à la pastorale, imitant le pape, la cour du roi s'est laissée dominer par la flatterie et le mensonge, l'impiété a gagné les chrétiens, le luxe a envahi les maisons, la sexualité s'est pervertie.

Et l'important est que c'est pour avertir les Français de leur corruption que Dieu leur a envoyé le protestantisme. L'autre, dans sa conversion à une foi différente, n'est donc plus qu'un agent de la miséricorde de Dieu, 
un appel à prendre conscience que chacun, en soi-même, doit procéder à un examen de conscience, doit se réformer et faire pénitence pour ses péchés. L'autre n'est plus à identifier dans un ailleurs, il est en soi tout d'abord. Il faut prendre conscience que celui qui s'est séparé de l'Eglise romaine est une aide envoyée par Dieu, une aide destinée à faire refluer l'autre qui est en soi hors de soi, et non pas l'envisager comme un rebelle qu'il serait urgent et nécessaire d'exterminer. C'est de cette situation particularisée que découle le respect et la "compassion" par lesquels sa présence dans la société civile doit être abordée. La division religieuse avertit les Français de ce qu'ils doivent avant tout s'amender dans la prière et la pénitence, face à un Dieu qui ne restaurera l'unité que lorsqu'il aura été satisfait dans son exigence $d^{\prime} u n e$ réformation qui n'est pas seulement ecclésiale mais éthique aussi.

Croire que l'on peut résoudre par l'"intolérance" et la violence éradicatrice le problème de la division religieuse, c'est vivre dans l'illusion, aller contre le désir de Dieu qui est d'abord miséricordieux. Dans la fin d'année 1560, Michel de L'Hospital ébauche une grande théorie de l'instabilité des peuples: à ses yeux, il y a un présupposé dont il faut tenir compte, qui est que la sédition, quelle qu'elle soit, même justifiée par une "[...] bonne et honneste cause", est pernicieuse. Elle relève du mal humain, d'une action par laquelle le croyant empiète sur ce qui n'appartient qu'à Dieu, dans l'ignorance de la faiblesse de son entendement' propre. Il faut noter que le chancelier emploie le terme "sédition" à la manière de Platon dans La République, au sens de trouble divisant la cité, c'est-à-dire de guerre civile. Comme Platon, d'ailleurs, il attribue la responsabilité de la violence à l'opinion des hommes, à la faculté qui juge sur les apparences, aux passions. Il vaut mieux accepter de souffrir toutes les oppressions, que d'être à l'origine d'un mal qui consiste à introduire la guerre civile dans sa patrie, un mal qui éloignera encore plus les Français de Dieu qu'ils ne le sont déjà dans le présent, puisque la présence hérétique les avertit de leur corruption et qu'utiliser la violence contre cette présence ne fera que les faire basculer dans toujours plus de passions.

Et même si la cause apparaît juste lorsqu'elle s'attache à défendre la religion, il n'en est pas moins vrai qu'elle se retourne contre elle-même, qu'elle nie sa justice dès qu'elle fait le choix d'user de la guerre civile et du refus de l'autre. La religion, dès qu'elle se fait sédition, se transforme en passion, se laisse recouvrir de la passion en ce qu'elle est contraire à la volonté de Dieu. En croyant aller vers Dieu par leur "intolérance", 
les hommes ne font que s'en séparer d'autant plus dramatiquement qu'ils utilisent le nom de Dieu pour donner libre cours au mal qui est en eux. Michel de L'Hospital consacre un grand développement pour prouver combien la "sédition" défait les liens les plus naturels, comme ceux du sang, en dressant les Français contre les Français jusque dans le cadre de la famille. C'est un monde à l'envers qui se concrétise dans la violence, à un point extrêmement tragique en ce qu'il défait tout ordre naturel et qu'il s'oppose fondamentalement à l'Evangile.

Laisser, par la loi du roi, le calvinisme cohabiter avec la foi des ancêtres, ce n'est pas toutefois accepter pour autant le calvinisme. C'est d'abord poser qu'il faut user de compassion, de charité à l'égard de ceux qui sont dans l'erreur non pas pour raison de leurs péchés mais pour cause des péchés du peuple, en châtiment divin des péchés du peuple. C'est ensuite poser que la société est un réseau de liens au premier plan desquels il y a la citoyenneté, l'appartenance à un Etat et à une culture qui sont communs à tous et qui obligent à vivre humainement les uns avec les autres, dans le rejet du meurtre et de la destruction. L'acceptation de l'autre est un acte de foi en la miséricorde de Dieu. Elle est une transcription du sola fide de l'évangélisme français. Il n'y a plus de haine cachant un amour destiné à faire de l'autre un même que soi, comme dans l'imaginaire calviniste, il n'y a plus d'amour qui doit se révéler dans une haine absolue et une éradication par laquelle l'autre cesse d'exister. Il n'y a plus qu'une immense méfiance à l'égard de soi, dans lequel la véritable altérité est tapie. C'est en soi que l'enjeu de l'altérité se règle prioritairement.

Les violences entre catholiques et huguenots, affirme encore le chancelier, par lesquelles chaque parti cherche à l'emporter sur l'autre et à conquérir le royaume à sa foi, ne font que plonger plus encore l'Etat et ses sujets dans le mal. Car imaginer que l'on peut réduire la division religieuse par la violence, par l'usage des passions qui procèdent cruellement et méchamment, $c^{\prime}$ est utiliser précisément le mal, aller encore plus loin dans le mal. Il ne revient pas aux hommes de mettre fin par leurs propres forces, humaines et marquées par la Faute, à ce qui est un châtiment de Dieu, car les violences sont des figures du mal pour lequel ils ont encouru la colère divine. La violence appartient à la sphère de la "philautie" érasmienne, la propension de l'homme à vouloir se mettre à la place de Dieu. Elle est un péché et ne peut en aucun cas, en toute logique, faire avancer l'histoire dans le sens d'un retour à l'unité. Il faut 
avant tout prier, demander pardon à Dieu pour les péchés qui ont valu au royaume l'apparition d'une foi concurrente. Seul Dieu peut mettre fin à la division religieuse, un jour que nul n'est en mesure de connaître.

Michel de L'Hospital vise avant tout à retirer les hommes d'un champ de pensées et d'actions qui, selon lui, ne dépend que de Dieu, la "concorde" a pour fin de les empêcher de vouloir se faire à l'égal de Dieu en tentant d'imposer leur foi. Dieu est tout-puissant, lui seul connaît le sens de l'histoire. Ce n'est pas aux hommes qu'il revient de décider de ce que seul Dieu connaît. Au contraire, il leur revient, par la paix, dans la paix que le pouvoir royal leur propose et impose, de se détacher de leurs passions, d'implorer le pardon divin qui est à l'origine de leurs dissensions, et alors, $s$ 'ils mettent toute leur foi dans la miséricorde divine, il y a la certitude, secrète et cachée dans les lignes mêmes de l'Edit de janvier, de ce que Dieu les ramènera tous dans un seul troupeau, dans un temps à venir que seul il sait.

L'œuvre politique de Michel de L'Hospital dissimule une œuvre de religion; elle a pour sens de créer ou d'instaurer une durée intermédiaire au cours de laquelle, précisément, dans la charité et dans sa force expansive, les hommes, dans un désengagement par rapport à leurs passions, aideront Dieu à exercer et à faire connaître le plus universellement possible sa justice mêlée de miséricorde. Il ne s'agit pas d'un temps autonomisé, laïcisé, il s'agit d'un temps de préparation de retour d'une société vers une plénitude de sacralité. Michel de L'Hospital ne croit pas en la "tolérance" qui demeure certainement pour lui marquée par une signification négative, il croit en la concorde dans la paix, parce que cette concorde est le premier palier qui préparera à une unité retrouvée, elle permettra la réforme de l’'Eglise romaine, et verra ceux qui s'en sont séparés, alors, la rejoindre quand, à force de foi et de pénitence, les cives français en seront revenus aux vertus de leurs ancêtres.

C'est au pouvoir royal qu'il revient de faire en sorte que les tentations de violence ne l'emportent pas. Le modèle du bon gouvernant est Salomon et non pas Moïse, David ou Josias. Il est celui d'un roi juge et arbitre tout à la fois. Le pouvoir est une responsabilité immense et le roi doit gouverner non pas pour lui mais pour tous, sans distinction de religions même s'il sait que les huguenots sont présents parmi son peuple comme instruments d'un message de Dieu à l'égard des Français, comme témoignages de ce qu'ils se sont éloignés de lui. En conséquence son travail l'astreint à avoir l'œil constamment sur ses sujets, sans marquer 
de préférence pour les uns ou les autres, à s'efforcer de tous les protéger du mal et des passions qui sont en eux, de les détourner, catholiques comme protestants, des désirs de violence qui ne peuvent que les éloigner de Dieu, de les remettre dans le droit chemin de la foi en la grandeur miséricordieuse de Dieu. Aidé par des conseillers choisis, il doit faire preuve de compassion à l'égard des erreurs dans lesquelles, par ignorance, ses sujets peuvent s'égarer. $\Pi$ ne faut pas chercher à user de violence contre les méchants et les injustes, ils ne sont méchants et injustes que par aveuglement, il doit user du pardon qui n'est pas une défaite pour l'autorité absolue, mais sa plus haute expression. En empêchant ses sujets de se déchirer les uns et les autres, il se met en scène comme un modèle, prouvant que l'amour prime sur la haine et donnant l'exemple d'une confiance dans des temps futurs qui verront la providence de Dieu refonder l'Alliance de son peuple sur son pardon. La violence est ce qui nie en conséquence la sainteté du souverain, ce contre quoi il doit lutter en supportant la division religieuse de son royaume, en supportant son caractère négatif avec espérance.

Ce qui ressort alors, est bien une pensée de la différence dans les moyens mais pas dans la fin. Les évangéliques français, qui vont se voir donner le surnom péjoratif de Politiques, croyaient que le temps de la division, qu'ils vivaient, n'était que provisoire. Ils ne vivaient eux-mêmes, dans leur foi, que dans l'attente d'un retour de l'unité. Mais leur représentation du temps reposait sur une conscience de la discontinuité au sein de laquelle l'homme ne devait pas chercher à interférer avec les desseins incompréhensibles de Dieu, au sein de laquelle le temps devait être vécu comme une continuité $d$ 'instants se succédant à eux-mêmes, sous le regard de Dieu, dans une posture d'amendement. Ni temps cyclique, ni temps linéaire, temps qui est ouvert à la charité et à la pénitence, excluant la violence, temps comme suspendu dans le cours duquel les hommes devaient faire le choix de l'amour en se supportant les uns les autres dans l'espérance qu'un jour leur serait rendue la grâce de l'Un, dans l'espérance seulement. Un temps en apparence humanisé, mais en réalité rendu totalement à Dieu.

L'autre, dans ce système alternatif, n'est pas accepté pour lui-même, pour sa foi, pour son Dieu, il ne l'est que comme signe de Dieu exprimant à travers lui sa colère pour les péchés du royaume. L'autre peut en conséquence exister, il peut survivre. Vivre avec lui est comme un test que l'homme est fragilité, un test de ce qu'il confesse que la vraie altérité, 
l'altérité première siège en lui. Ainsi, dans le cours d'une durée comme suspendue à l'attente de la miséricorde divine, le fait même de vivre à ses côtés sans l'offenser ou le tuer devient un contre-signe envoyé à Dieu de ce que son message a été compris ou entendu, de ce que l'humanité cherche à revenir à la fidélité et à la vertu, de ce qu'il est une chance pour tous. Au terme inconnaissable de cette durée, il cesserait d'être un autre en même temps que soi-même on cesserait d'être autre à Dieu. La pensée de l'autre est, sans le recours à la violence, l'annihilation de l'autre. Le modèle de la démarche de Michel de L'Hospital est donc un exclusivisme qui ne se dit pas. De là découle, comme on le verra, que la Politique ne peut pas être pour lui une fin en soi, mais qu'elle est un moyen par lequel le gouvernant met sa foi dans la miséricorde divine, prépare en quelque sorte un retour de Dieu parmi son peuple, entreprend de ruser avec les passions. La dissociation du Politique et du Religieux n'est qu'une apparence, même elle est comme la manifestation d'une parole qui suit le Christ qui, par sa parole, a usé de ruse et de tromperie lors des temps de sa prédication; le Politique initie, par l'équilibre qu'il instaure et la paix que cet équilibre doit ramener, un mouvement de recomplétude sacrale, mais dont Dieu seul sait le moment de la perpétuation finale. Il aide seulement Dieu dans la faible mesure de sa foi en sa justice et miséricorde. La politique est donc une expression de la foi, elle est religieuse jusqu'au plus profond, parce qu'elle est avant tout une espérance qui, dans le quotidien de tous les jours, un quotidien dédramatisé, vit la foi au côté de l'autre pour que l'autre, comme soi-même, un jour, puisse pleinement revenir à Dieu. Face à l'altérité, le chrétien doit être imperturbablement attentif à s'opposer à tous ceux qui voudraient la nier ou la détruire. Il doit être intolérant avec l'intolérance, car c'est avec l'autre, par l'autre, que l'on peut espérer accéder à la vérité de soi, la restituer à elle-même en se reconnaissant infiniment pécheur face à un Dieu infiniment bon. L'autre est nécessaire à soi, il se découvre comme le devoir de soi.

\section{Conclusion}

Le XVIe siècle, en conséquence, $n$ 'invente pas la tolérance, il invente une intolérance de l'intolérance qui n'en dissimule pas moins un autre exclusivisme dans le cadre d'une représentation du temps abandonné à 
la miséricorde divine, figure de pardon et de charité. Il est évident que l'Edit de Nantes porte en lui la mémoire de cette invention de 1562. Il visait à instaurer, précisément, un espace de temps au cours duquel, dans la paix, les sujets, de quelque confession il soient, se glisseraient dans l'ordre des désirs divins. Il se projetait dans un rêve d'unité restauré dont il était un instrument. Mais si l'on en revient à Michel de L'Hospital, on peut ajouter que le temps, suspendu dans l'espérance, est comme manipulé par le gouvernant, par la foi du gouvernant.

Erasme fut peut-être le croyant d'une certaine dualité. C'est dans les Paraphrases que le mot tolerantia apparaît: Dieu "tolère" les impies. Il a même supporté (passus est) longuement que ses disciples demeurent ignorants. Jacques Chomarat a insisté sur un fait qui peut être capital pour comprendre les mécanismes intellectuels de la volonté de paix de Michel de L'Hospital et de sa construction d'une figure de souverain idéal: Erasme s'attarde sur la prudence et la dissimulation du Christ aux pèlerins d'Emmaüs. Le Christ put aller jusqu'à ruser et tromper, à tendre un piège au Tentateur: il peut y avoir une tromperie chrétienne face au mensonge diabolique, mais elle est exercée provisoirement et elle est inspirée par la charité. Il s'agit de la mise en action d'un désir de faire du bien à autrui malgré lui, sans qu'il en ait la conscience claire. Il faut se remémorer, écrit Erasme, "[...]comment le Christ qui ne saurait mentir, peut tromper... il trompe les apôtres: afin d'arracher complètement de leur âme tout désir de vengeance, il les trompe pour un temps par l'obscurité de son langage, mais il ne les laisse dans l'erreur qu'afin de détruire plus sûrement et plus efficacement toute leur passion de se venger". La tolerantia, pour Erasme, ne doit pas être comprise comme "[...] le partage des erreurs". Elle est une décision assumée en toute conscience de "patiemment supporter" les erreurs des autres parce que seul Dieu est en mesure de mettre fin à ces erreurs, "elle compte sur le temps, dans les Paraphrases, et sur la douceur pour faire disparaître l'erreur et non sur la violence".

Ce fonctionnement christique de la tolerantia érasmienne peut suggérer une hypothèse. Michel de L'Hospital, par acte de foi en la justice et miséricorde du Christ, ne fut-il pas, contre le malheur de son temps, un théoricien et un praticien de la ruse? Ne doit-il pas être compris comme un chancelier de la ruse, cherchant à prendre au piège de sa paix tous ceux qui, de part et d'autre de la foi évangélique, s'opposaient avec virulence et intransigeance et qui, à ses yeux, étaient plongés dans 
l'ignorance d'eux-mêmes et donc de Dieu? La paix n'avait-elle pas pour fin, une fois le pardon divin atteint grâce à la réforme de l'Eglise, de la justice et des mœurs du royaume, de laisser à Dieu la puissance de ramener tous les sujets du roi dans une unité de religion, dont Michel de L'Hospital ne doutait pas qu'elle était la pure religion évangélique? Tous n'étaient-ils pas, selon des échelles de gradation différentes, envahis par l'altérité, tous ne partageaient-ils pas l'altérité? Ce fut bien un troisième exclusivisme qui se cacha dans ce qui, par effet $d^{\prime}$ un mirage de la rétrospectivité, peut se laisser voir sous l'apparence d'une modernité. 